\title{
Alternative conduits for esophageal replacement
}

\author{
Ankur Bakshi, David J. Sugarbaker, Bryan M. Burt \\ Division of Thoracic Surgery, Michael E. DeBakey Department of Surgery, Baylor College of Medicine, Houston, TX, USA \\ Correspondence to: Bryan M. Burt, MD. Division of Thoracic Surgery, Michael E. DeBakey Department of Surgery, Baylor College of Medicine, One \\ Baylor Plaza, MS BCM: 390, Houston, TX 77030, USA. Email: Bryan.Burt@bcm.edu.
}

\begin{abstract}
Replacement of the native esophagus after esophagectomy is a problem that has challenged surgeons for over a century. Not only must the conduit be long enough to bridge the distance between the cervical esophagus and the abdomen, it must also have a reliable vascular supply and be sufficiently functional to allow for deglutition. The stomach, jejunum, and colon (right, left or transverse) have all been proposed as potential solutions. The stomach has gained favor for its length, reliable vascular supply and need for only a single anastomosis. However, there are times when the stomach is unavailable for use as a conduit. It is in these instances that an esophageal surgeon must have an alternative conduit in their armamentarium. In this paper, we will briefly discuss the technical aspects of jejunal and colonic interposition. We will review the recent literature with a focus on early and late outcomes. The advantages and disadvantages of both options will be reviewed.
\end{abstract}

Keywords: Esophagectomy; jejunum; colon interposition; Roux-en-Y jejunostomy; esophageal

Submitted Jan 07, 2017. Accepted for publication Jan 18, 2017.

doi: 10.21037/acs.2017.03.07

View this article at: http://dx.doi.org/10.21037/acs.2017.03.07

\section{Introduction}

Re-establishment of gastrointestinal continuity is a critical determinant of quality of life following esophagectomy. An ideal replacement for the esophagus that can mimic all of its functions does not currently exist. Such a replacement would have sufficient length to bridge the cervical or upper thoracic esophagus with the gastrointestinal tract of the abdomen. It would require a robust vascular pedicle that would maintain perfusion along the entire distance of conduit and provide more than sufficient perfusion of its distal end to minimize anastomotic problems. The ideal esophageal replacement would also have intrinsic motility to facilitate transit of food boluses and minimize reflux.

Current options for esophageal replacement include the stomach, the right and left colon, and the jejunum. Like many esophageal surgeons, we prefer to fashion the conduit from stomach when it is available. Owing to its sufficient length, predictable vascular supply, and requirement of only a single anastomosis, the stomach is a time-honored and reliable conduit. There are instances, however, when the stomach is unavailable for use. Examples of such situations include caustic ingestions where both the esophagus and stomach have been critically injured. Prior gastrectomy and previous abdominal surgery in which primary arterial supply to the conduit, the right gastroepiploic artery, has been sacrificed will preclude the use of a gastric pull-up. Not uncommonly, gastric extension of distal esophageal tumors or true gastroesophageal junction tumors are encountered which result in use of the stomach as oncologically unfeasible. In some patients, a previous gastric conduit may fail due to ischemic necrosis, recalcitrant strictures or even recurrent or de novo cancer. In such cases, an alternative conduit must be selected.

\section{Colonic interposition}

Colonic interposition has been used for esophageal reconstruction since the early 1900s (1). Either the left or right colon may be utilized and in either case, the transverse colon is always required. Proponents of colonic interposition recommend this option in many cases for its substantial length. The length of a right colon interposition for example, closely simulates that of the native esophagus. Another benefit of the colon is its resistance to acid and the right colonic interposition includes the valve of Bauhim 

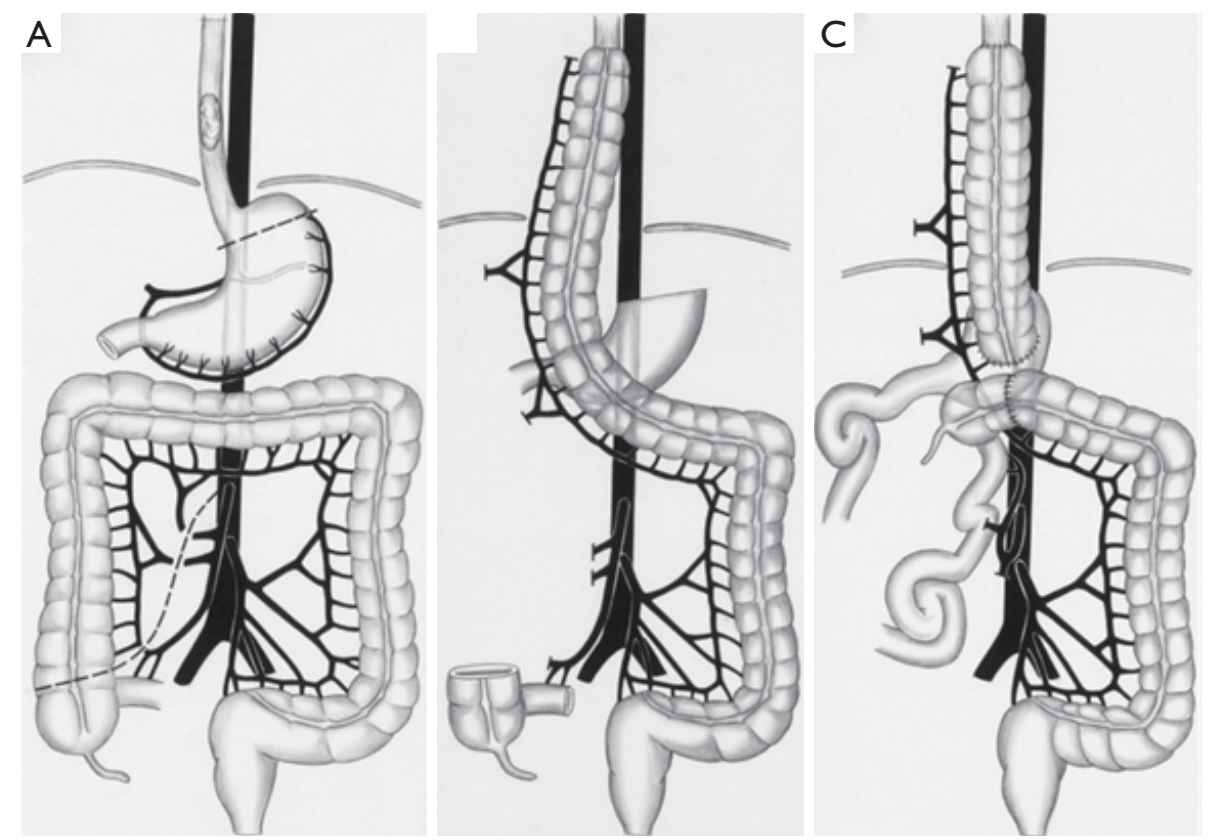

Figure 1 Isoperistaltic right colon interposition. (A) Creating of the interposition graft; (B) construction of the cervical anastomosis; (C) reconstruction of intestinal continuity. Source: Fürst et al. (5).

which may further decrease reflux (2). Disadvantages of the colonic interposition include that the colon may have or can develop native pathology and that loss of absorptive capacity of the colon may result in diarrhea (3). The colon conduit may also lengthen over time leading to redundancy that may require surgical revision (4).

\section{Preoperative evaluation}

A thorough surgical history must be elicited to determine if the patient has had a procedure that may have compromised the follow to the vascular pedicle. A history of ischemic colitis, or Crohn's or ulcerative colitis should be investigated as these processes generally will preclude colonic interposition. Preoperative colonoscopy should be performed to rule out any intrinsic pathology within the colon that would prevent it use. Further, a computed tomography (CT) arteriogram is useful to evaluate the patency and robustness of the superior and inferior mesenteric arteries, and the ileocolic, right, middle, and left colonic arteries, particularly in cases when prior interventions may have affected the surgical anatomy.

\section{Technical considerations}

In preparation for conduit construction, the entire colon must be mobilized and the vascular anatomy of the colon is then carefully interrogated. The graft can utilize either the right or left colon. Importantly, the vascular supply to the right colon is more variable than that of the left colon. For example, some patients do not have a right colic artery and some patients also lack the vascular arcade that connects the middle colic arterial supply to the right colic arterial supply (1). Our preference for colon interposition is a right colon interposition, which is described in detail below. The left colon interposition requires preservation of the vascular arcade between the upper left colic and right colic vessels and requires exposure and ligation of the main middle colic artery with preservation of its left and right divisions.

We prefer to use an isoperistaltic right colon interposition according to the technique described by Fürst et al. (5). This graft is based exclusively off the inferior mesenteric artery, and the ascending colon is ultimately "swung" up into the mediastinum (Figure 1). After mobilizing the entire colon, the mesentery of the colon is splayed and transillumination is used to identify and clamp the middle colic, right colic, and connection between the ileocolic and right colic artery, temporarily using vascular clamps. Once adequate perfusion and viability of the conduit is assured, it is isolated from these arteries by 


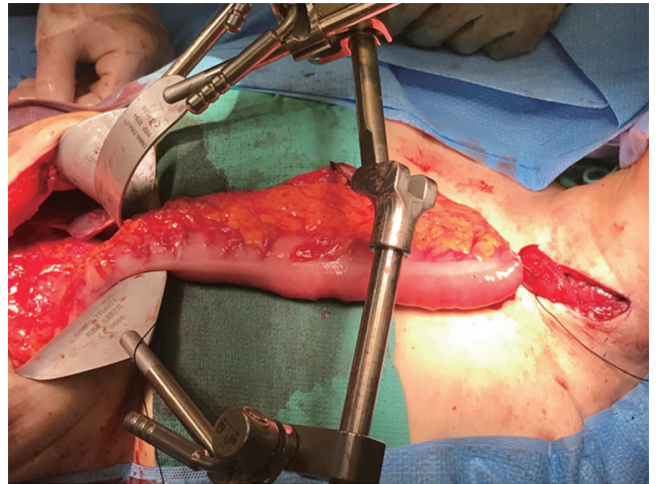

Figure 2 Right colon interposition graft prior to delivery through the mediastinum and cervical anastomosis. Source: Bryan M. Burt, MD.

division of the right and middle colic arteries and ligated proximally. The ascending colon is transected just above the cecum and the mesentery of the colon is then divided close to the takeoff branches of the vessels to prevent injury to collaterals. The esophagus is removed using conventional techniques.

The colonic graft may be positioned in the posterior mediastinum, retrosternal, or substernal (Figure 2). If the conduit is tunneled in the substernal position, it is recommended to widen of the thoracic inlet by resection of the left hemimanubrium, a portion of the left clavicle and a portion of the left first rib (3). Our preferred position for the colonic position is through the posterior mediastinum and an esophagocolonic anastomosis is fashioned in the left neck. The colon graft is atraumatically delivered into the neck by placing the conduit into a plastic laparoscopy camera cable covering sheath that is fashioned to a Foley catheter allowing gentle suction to be placed into the bag and gently securing the conduit in place for its travel through the mediastinum (6). The colon is then anastomosed to the cervical esophagus by the surgeon's preferred anastomosis. The surgeon will be reliably pleased to find more than adequate length and a well perfused distal conduit in the neck for anastomosis. The colon is then divided at the splenic flexure and anastomosed either to the gastric remnant in the abdomen or to a Roux-en-Y limb of jejunum (in cases of total esophagogastrectomy). The colo-colonic anastomosis is then completed. In cases where the arterial supply is deemed inadequate at the distal end of the conduit, supercharging, where a microvascular arterial anastomosis is performed in the neck, may be done. If venous drainage is deemed inadequate, superdrainage, where a microvascular venous anastomosis is performed in the neck, may be performed (7).

\section{Results}

A number of case series report institutional experience with colon interpositions and detailed results of these series are summarized in Table 1 (1,7-21). Rates of reported graft loss were $0-14 \%$. In the larger case series, this range decreases to $0-2 \%$. The reported anastomotic leak rate was $0-50 \%$ and in larger case series, this rate decreases to $0-12.6 \%$. Mortality ranged from $0-16.7 \%$ and in centers with higher case volume, this rate was $0-7 \%$. The long term stricture rate was 0 to $32 \%$. The re-operative rate was $0-32 \%$ and reasons for re-operation included graft necrosis, graft redundancy, and anastomotic leaks. The most commonly reported medical complication was aspiration and pneumonia which had a rate of $0-32 \%$. Resumption of oral intake has been reported between $75 \%$ and $100 \%$.

\section{Jejunum}

The jejunum has been used since the times of Roux in the early 1900s as a conduit for reconstruction after esophagectomy (22). In 1946, Longmire, proposed vascular augmentation of jejunal conduits, also known as "supercharging," to enhance the vascular supply of the conduit and to decrease risks of ischemia (23). Proponents of this conduit recommend the jejunum because it has a reliable blood supply, which is clearly enhanced at the level of the anastomosis with the supercharged technique. There is also significant amount of redundant jejunum so the patient will not be harmed by loss of that length of jejunum, and the jejunum tends to lack intrinsic pathology. The jejunum also has intrinsic peristalsis, which has potential benefits for quality of life. Disadvantages of the supercharged jejunal conduit include the need for a microvascular anastomosis with its associated extension of operating time and technical complexity (24). In certain instances, jejunal conduits may not be long enough to reach the hypopharynx. Fatty mesentery may also inhibit the surgeon's ability to pull up the conduit (25).

\section{Preoperative considerations}

As with colon interpositions, a thorough medical and surgical history should be obtained. Although not universally adopted, some surgeons have described use 


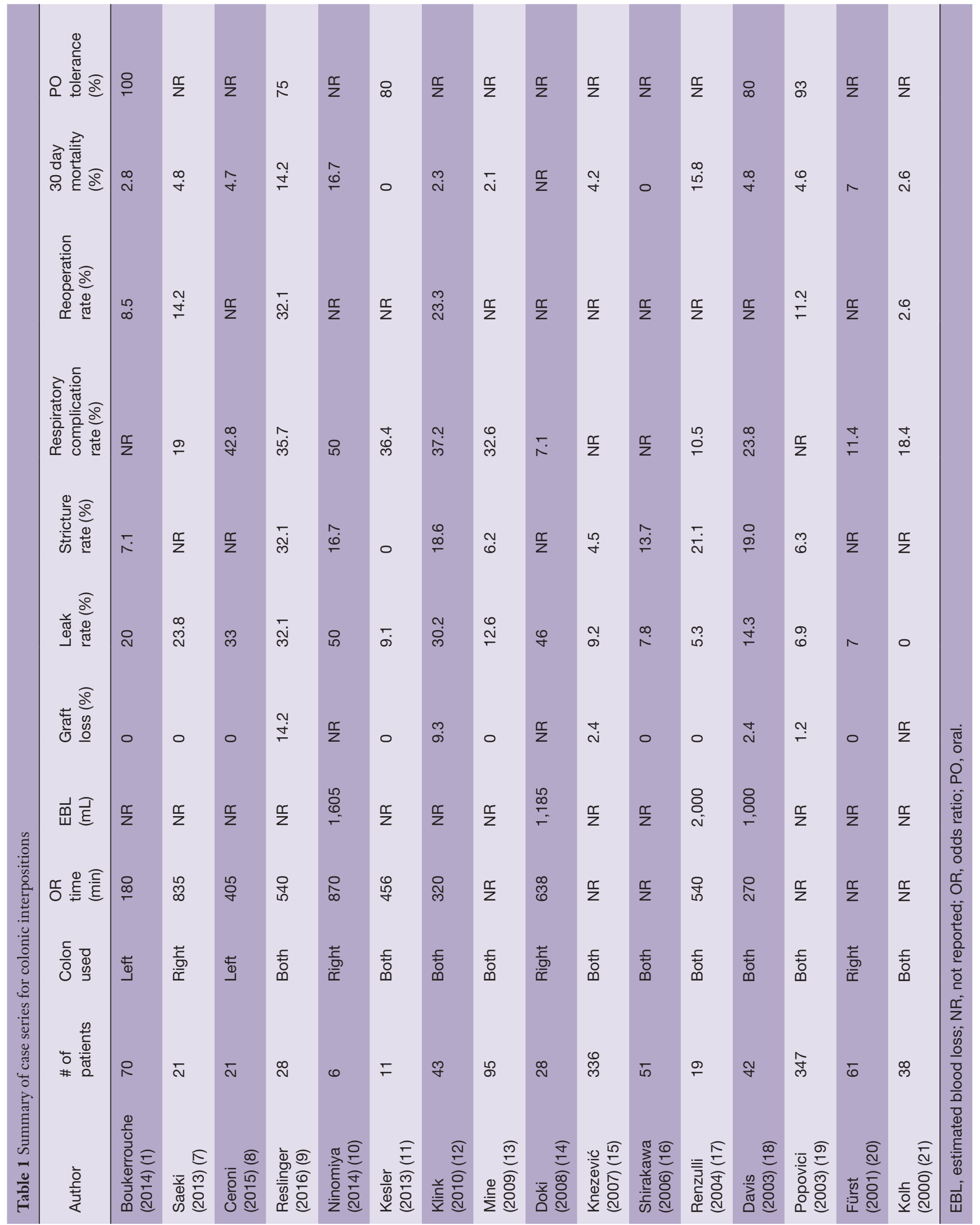




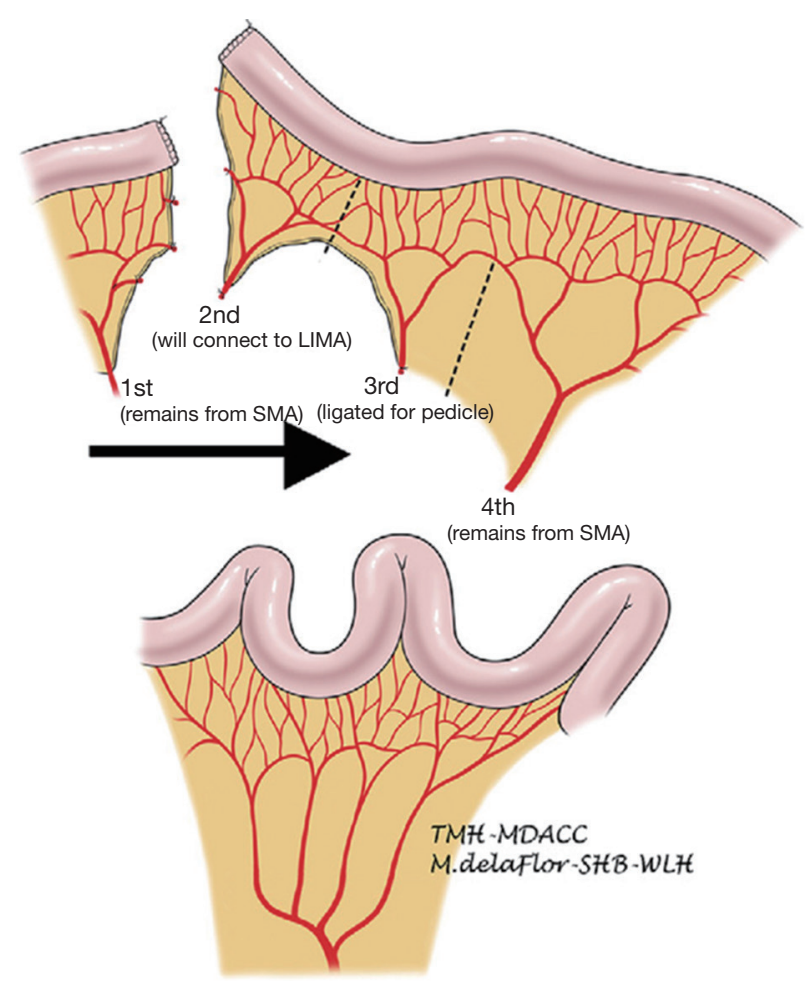

Figure 3 Vascular arcade pattern of the jejunum and division of the vasculature and mesentery for creation of the jejunal conduit. Source: Blackmon et al. (22).

of a preoperative CT angiography to facilitate surgical planning (24).

\section{Technical considerations}

A segment of jejunum is selected approximately $20 \mathrm{~cm}$ from the ligament of Treitz. The first jejunal arterial branch is preserved. The second jejunal branch is divided with the intention of using it to augment the vascular supply of the graft in the next. The third jejunal branch is also divided. The fourth jejunal branch is preserved to supply the rest of the conduit (22). Because the jejunum has a foreshortened mesentery, the mesentery must be divided to straighten the conduit and prevent redundancy (Figure 3). Similar to the colonic interposition, the jejunal conduit may be tunneled through the posterior mediastinum, or situated in the retrosternal or substernal position. The left hemimanubrium, a portion of the medial left clavicle and a portion of the medial left first rib must be resected to expand the thoracic inlet and to facilitate exposure of the internal thoracic artery and vein. The second jejunal branch and its vein are then anastomosed to the internal thoracic artery and vein or an alternative suitable inflow and outflow vessel. The arterial anastomosis is typically done with 9-0 suture under a microscope, and commonly is done in collaboration with a microvascular plastic surgeon. The venous anastomosis can be done in a similar fashion or with a venous coupler. Venous couplers are comprised of rings and pins that are used to promote apposition of the intima of vessels and have been adapted in microvascular surgery (26). The jejunum can then be anastomosed to the esophagus by the surgeon's preferred method of anastomosis. In the abdomen, the conduit can be anastomosed to the stomach, typically on the posterior aspect, or to jejunum in a Roux-en-Y jejunostomy. A segment of jejunum not involved in the anastomosis may be transposed extracorporeally to serve as a flap monitor.

\section{Results}

A variety of cases series describing institutional experience with supercharged jejunal conduits and detailed results of these series are summarized in Table 2 (10,14,22,25,27-32). Post-operatively, the reported rates of graft loss ranged from $0-8 \%$. Reported rates of anastomotic leak rate ranged $0-36 \%$. Rates of reoperation are reported from $0-50 \%$ and reasons for re-operation included anastomotic leak, graft loss, graft redundancy, and non-graft related jejunal ischemia. In hospital mortality was $0-5 \%$. The most commonly reported complication was aspiration and pneumonia which was $7-30 \%$. Long term outcomes have been reported in small series. Tolerance of a regular diet was found in $80-100 \%$ of patients. Blackmon et al. performed manometry on five patients and found that peristalsis was preserved in their jejunal grafts (22). Baker et al. performed quality of life surveys on their patients which were overall quite favorable (27).

\section{Synthesis}

The use of non-gastric conduits after esophagectomy is often a salvage procedure and interpretation of the results of series describing outcomes following colon and jejunal interpositions should take this into consideration. Taken together with the technical complexity of interposition procedures, the published rates of morbidity and mortality are highly variable. In experienced hands, construction of colon and jejunal conduits can be performed with excellent short-term and long-term results. Owing to its more than sufficient length, its robust blood supply, and its non- 


\begin{tabular}{|c|c|c|c|c|c|c|c|c|c|c|}
\hline $\begin{array}{l}\text { Ninomiya } \\
(2014)(10)\end{array}$ & 13 & 715 & 730 & NR & 0 & 23.1 & 23.1 & NR & 0 & NR \\
\hline $\begin{array}{l}\text { Blackmon } \\
\text { (2014) (22) }\end{array}$ & 60 & NR & NR & 8.3 & 32 & NR & 30 & 31.7 & 5 & 93.3 \\
\hline $\begin{array}{l}\text { Iwata } \\
(2012)(25)\end{array}$ & 27 & 636 & 580 & 0 & 7.4 & 3.7 & 7.4 & 3.7 & 0 & 100 \\
\hline $\begin{array}{l}\text { Poh } \\
\text { (2011) (29) }\end{array}$ & 51 & NR & NR & 5.9 & 11.7 & 9.8 & 37.3 & 15.7 & 0 & 90 \\
\hline $\begin{array}{l}\text { Barzin } \\
(2011)(30)\end{array}$ & 5 & 467 & NR & 0 & 20 & NR & NR & 20 & 0 & 100 \\
\hline $\begin{array}{l}\text { Ascioti } \\
(2005)(31)\end{array}$ & 26 & 726 & 1,441 & 7.7 & 19.2 & NR & 30.8 & 11.5 & 0 & 95.2 \\
\hline $\begin{array}{l}\text { Chana } \\
(2002)(32)\end{array}$ & 11 & NR & NR & 0 & 36.4 & 18.2 & NR & 90.9 & 0 & 100 \\
\hline
\end{tabular}

dependence of a microvascular anastomosis, our personal preference is an isoperistaltic right colon interposition when the gastric conduit is not available.

\section{Acknowledgements}

None.

\section{Footnote}

Conflicts of Interest: The authors have no conflicts of interest to declare.

\section{References}

1. Boukerrouche A. Isoperistaltic left colic graft interposition via a retrosternal approach for esophageal reconstruction in patients with a caustic stricture: mortality, morbidity, and functional results. Surg Today 2014;44:827-33.
2. Yasuda T, Shiozaki H. Esophageal reconstruction with colon tissue. Surg Today 2011;41:745-53.

3. DeMeester SR. Colonic Interposition for Benign Disease. Oper Tech Thorac Cardiovasc Surg 2006;11:232-49.

4. Strauss DC, Forshaw MJ, Tandon RC, et al. Surgical management of colonic redundancy following esophageal replacement. Dis Esophagus 2008;21:E1-5.

5. Fürst H, Hartl WH, Löhe F, et al. Colon interposition for esophageal replacement: an alternative technique based on the use of the right colon. Ann Surg 2000;231:173-8.

6. Korst RJ, Sukumar M, Burt ME, et al. Atraumatic gastric transposition after transhiatal esophagectomy. Ann Thorac Surg 1997;64:867-9.

7. Saeki H, Morita M, Harada N, et al. Esophageal replacement by colon interposition with microvascular surgery for patients with thoracic esophageal cancer: the utility of superdrainage. Dis Esophagus 2013;26:50-6.

8. Ceroni M, Norero E, Henríquez JP, et al. Total esophagogastrectomy plus extended lymphadenectomy 
with transverse colon interposition: A treatment for extensive esophagogastric junction cancer. World J Hepatol 2015;7:2411-7.

9. Reslinger V, Tranchart H, D'Annunzio E, et al. Esophageal reconstruction by colon interposition after esophagectomy for cancer analysis of current indications, operative outcomes, and long-term survival. J Surg Oncol 2016;113:159-64.

10. Ninomiya I, Okamoto K, Oyama K, et al. Feasibility of esophageal reconstruction using a pedicled jejunum with intrathoracic esophagojejunostomy in the upper mediastinum for esophageal cancer. Gen Thorac Cardiovasc Surg 2014;62:627-34.

11. Kesler KA, Pillai ST, Birdas TJ, et al. "Supercharged" isoperistaltic colon interposition for long-segment esophageal reconstruction. Ann Thorac Surg 2013;95:1162-8; discussion 1168-9.

12. Klink CD, Binnebösel M, Schneider M, et al. Operative outcome of colon interposition in the treatment of esophageal cancer: a 20-year experience. Surgery 2010;147:491-6.

13. Mine S, Udagawa H, Tsutsumi K, et al. Colon interposition after esophagectomy with extended lymphadenectomy for esophageal cancer. Ann Thorac Surg 2009;88:1647-53.

14. Doki Y, Okada K, Miyata H, et al. Long-term and shortterm evaluation of esophageal reconstruction using the colon or the jejunum in esophageal cancer patients after gastrectomy. Dis Esophagus 2008;21:132-8.

15. Knezević JD, Radovanović NS, Simić AP, et al. Colon interposition in the treatment of esophageal caustic strictures: 40 years of experience. Dis Esophagus 2007;20:530-4.

16. Shirakawa Y, Naomoto Y, Noma K, et al. Colonic interposition and supercharge for esophageal reconstruction. Langenbecks Arch Surg 2006;391:19-23.

17. Renzulli P, Joeris A, Strobel O, et al. Colon interposition for esophageal replacement: a single-center experience. Langenbecks Arch Surg 2004;389:128-33.

18. Davis PA, Law S, Wong J, et al. Colonic interposition after esophagectomy for cancer. Arch Surg 2003;138:303-8.

19. Popovici Z. A new philosophy in esophageal reconstruction with colon. Thirty-years experience. Dis Esophagus 2003;16:323-7.

20. Fürst H, Hüttl TP, Löhe F, et al. German experience with colon interposition grafting as an esophageal substitute. Dis Esophagus 2001;14:131-4.

21. Kolh P, Honore P, Degauque C, et al. Early stage results after oesophageal resection for malignancy - colon interposition vs. gastric pull-up. Eur J Cardiothorac Surg 2000;18:293-300.

22. Blackmon SH, Correa AM, Skoracki R, et al. Supercharged pedicled jejunal interposition for esophageal replacement: a 10-year experience. Ann Thorac Surg 2012;94:1104-11; discussion 1111-3.

23. Longmire WP Jr, Ravitch MM. A new method for constructing an artificial esophagus. Ann Surg 1946;123:819-35.

24. Swisher SG, Hofstetter WL, Miller MJ, et al. The supercharged microvascular jejunal interposition. Semin Thorac Cardiovasc Surg 2007;19:56-65.

25. Iwata N, Koike M, Kamei Y, et al. Antethoracic pedicled jejunum reconstruction with the supercharge technique for esophageal cancer. World J Surg 2012;36:2622-9.

26. Chang KP, Lin SD, Lai CS, et al. Clinical experience of a microvascular venous coupler device in free tissue transfers. Kaohsiung J Med Sci 2007;23:566-72.

27. Baker CR, Forshaw MJ, Gossage JA, et al. Long-term outcome and quality of life after supercharged jejunal interposition for oesophageal replacement. Surgeon 2015;13:187-93.

28. Shirakawa Y, Noma K, Koujima T, et al. Operative technique of antethoracic esophageal reconstruction with pedicled jejunal flap. Esophagus 2015;12:57-64.

29. Poh M, Selber JC, Skoracki R, et al. Technical challenges of total esophageal reconstruction using a supercharged jejunal flap. Ann Surg 2011;253:1122-9.

30. Barzin A, Norton JA, Whyte R, Supercharged Jejunum Flap for Total Esophageal Reconstruction: Single-Surgeon 3-Year Experience and Outcomes Analysis. Plast Reconstr Surg 2011;127:173-80.

31. Ascioti AJ, Hofstetter WL, Miller MJ, et al. Longsegment, supercharged, pedicled jejunal flap for total esophageal reconstruction. J Thorac Cardiovasc Surg 2005;130:1391-8.

32. Chana JS, Chen HC, Sharma R, et al. Microsurgical reconstruction of the esophagus using supercharged pedicled jejunum flaps: special indications and pitfalls. Plast Reconstr Surg 2002;110:742-8; discussion 749-50.

Cite this article as: Bakshi A, Sugarbaker DJ, Burt BM. Alternative conduits for esophageal replacement. Ann Cardiothorac Surg 2017;6(2):137-143. doi: 10.21037/ acs.2017.03.07 